\title{
Spectrophotometry of six high-excitation compact H II regions in the Magellanic Clouds
}

\author{
Gérard Testor \\ Laboratoire de l'Univers et de ses Theories, \\ Observatoire de Paris-Meudon, F-92195 Meudon, la France
}

\begin{abstract}
Series of CCD long-slit spectra have been obtained in the 3600 $10000 \AA$ range, with the ESO $1.5 \mathrm{~m}$ telescope, for the six brightest compact HII regions in the LMC and SMC: N11A, N $160 \mathrm{~A} 1-\mathrm{A2}$ and N88A, N 81 and N 26A-B, respectively. For each region the spectral type of its complex exciting source is given. From the emission-line intensities we have derived the gas electron density and temperature, and computed the chemical abundances of $\mathrm{He}, \mathrm{O}$, $\mathrm{N}, \mathrm{Ne}, \mathrm{S}$, and $\mathrm{Ar}$, which we compare with the ones found for other $\mathrm{H}$ II regions in the Magellanic Clouds.
\end{abstract}

\section{Introduction}

Compact H II regions or high-excitation 'blobs' (HEBs) have been associated with the birth of massive stars in the Magellanic Clouds (MCs). HEBs are extremely bright, and due to their size (FWHM $\approx 0.9-2.2 \mathrm{pc}$ ) are well adapted to study individual regions. Since 1982, only eight HEBs have been discovered in the MCs (Testor 2001). Recently, a detailed HST study of seven HEBs by Charmandris (2001) showed that HEBs are not excited by single massive stars. One of these HEBs, N88A, was also studied by Kurt et al. (1999). Because of dust extinction and strong nebular pollution, uncertainties still subsist, especially in the spectral type determination of the exciting stellar sources. This contribution, that deals with the HEBs: N 88A, N 81, N 26A-B, in the SMC and $\mathrm{N} 11 \mathrm{~A}$ and $\mathrm{N} 160 \mathrm{~A}, \mathrm{~B}$ in the LMC, presents new results on spectral type of the composite stellar sources and on element abundances in the ionized gas.

\section{Observations and results}

Long- and short-exposure long-slit blue and near infrared spectra of low-spatial resolution have been obtained across each $\mathrm{HEB}$, during several runs using the B\&C spectrograph on the ESO $1.5 \mathrm{~m}$ telescope. These numerous spectra allow not only to increase the $\mathrm{s} / \mathrm{N}$, but also to obtain a homogeneous dataset.

Figure 1 displays the optical spectra of six HEB ionization composite sources, showing clearly the He II $\lambda 4541$ and He II $\lambda 4586$ absorption lines. In the case of N11A and N81, when the nebular subtraction was possible, the He I $\lambda 4471$ absorption profile is overplotted. The equivalent spectral types are derived comparing our data with the atlas of Walborn \& Fitzpatrick (1990), and are give in Figure 1.

The physical parameters of the nebulae were computed using a five-level atom code, with atomic data as described by Stasińska and Leitherer (1996). 

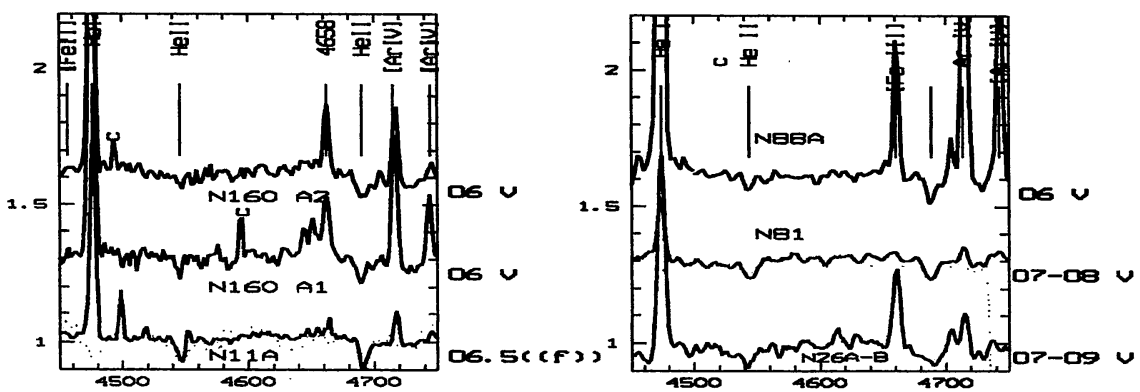

Figure 1. E-W rectified spectra and spectral types of each complex ionizing source. The dotted lines spectra include the nebular suppression.

Table 1. Element abundances derived from the nebulae in the form $(12+\log [\mathrm{N}(\mathrm{X}) / \mathrm{N}(\mathrm{H})])$.

\begin{tabular}{|c|c|c|c|c|c|c|c|c|}
\hline name & 0 & $\mathrm{~N}$ & $\mathrm{Ne}$ & $\mathrm{Ar}$ & $\mathrm{S}^{S}$ & $\mathrm{He}$ & $\mathrm{c}(\mathrm{H} \beta)$ & slit(") \\
\hline $\begin{array}{l}\text { N26A-B }^{97} \\
\text { N81 }^{92} \\
\text { N88A }^{97}\end{array}$ & $\begin{array}{l}7.93 \pm 0.03 \\
8.03 \pm 0.04 \\
7.94 \pm 0.03\end{array}$ & $\begin{array}{l}6.58 \pm 0.03 \\
6.48 \pm 0.04 \\
6.40 \pm 0.05\end{array}$ & $\begin{array}{l}7.19 \pm 0.03 \\
7.29 \pm 0.04 \\
7.26 \pm 0.03\end{array}$ & $\begin{array}{l}5.74 \pm 0.04 \\
5.91 \pm 0.05 \\
5.67 \pm 0.04\end{array}$ & $\begin{array}{l}6.31 \pm 0.05 \\
6.25 \pm 0.05\end{array}$ & $\begin{array}{l}10.93 \\
10.88 \\
10.95\end{array}$ & $\begin{array}{l}0.58 \\
0.32 \\
0.35\end{array}$ & $\begin{array}{l}4 \\
2 \\
4\end{array}$ \\
\hline $\begin{array}{l}\mathrm{SMC}^{G} \\
\mathrm{~N}^{\prime} 8 \mathrm{~A}^{K}\end{array}$ & $\begin{array}{l}8.0 \\
7.96 \pm 0.07\end{array}$ & $\begin{array}{l}6.5 \\
6.39 \pm 0.14\end{array}$ & $\begin{array}{l}7.2 \\
7.14 \pm 0.10\end{array}$ & $\begin{array}{l}5.9 \\
5.57 \pm 0.20\end{array}$ & $\begin{array}{l}6.3 \\
6.34 \pm 0.16\end{array}$ & 10.93 & 0.5 & 2 \\
\hline $\begin{array}{l}\mathrm{N} 11 \mathrm{~A}^{97} \\
\mathrm{~N} 160 \mathrm{~A} 1^{92} \\
\mathrm{~N} 160 \mathrm{~A} 2^{92}\end{array}$ & $\begin{array}{l}8.30 \pm 0.03 \\
8.42 \pm 0.04 \\
8.33 \pm 0.04\end{array}$ & $\begin{array}{l}6.99 \pm 0.03 \\
7.13 \pm 0.05 \\
6.97 \pm 0.05\end{array}$ & $\begin{array}{l}7.54 \pm 0.03 \\
7.71 \pm 0.05 \\
7.58 \pm 0.05\end{array}$ & $\begin{array}{l}6.16 \pm 0.03 \\
6.21 \pm 0.03 \\
6.17 \pm 0.03\end{array}$ & $6.75 \pm 0.05$ & $\begin{array}{l}10.94 \\
10.95 \\
10.91\end{array}$ & $\begin{array}{l}0.22 \\
0.50 \\
0.68\end{array}$ & $\begin{array}{l}4 \\
2 \\
2\end{array}$ \\
\hline $\mathrm{LMC}^{G}$ & 8.40 & 6.9 & 7.6 & 6.2 & 6.7 & & & \\
\hline
\end{tabular}

Notes: $G$ : Garnett (1999); $K$ : Kurt et al. (1999); $S$ derived when [S III] $\lambda 9532$ line was available; 92, 97: 1992, 1997 observations.

The emission-line intensities were corrected for reddening (Seaton 1979). Using the derived mean electron gas temperature $T_{\mathrm{e}}[\mathrm{O} \mathrm{III}]$ and the mean electron densities $n_{\mathrm{e}}[\mathrm{SII}]$, the elemental abundances have been calculated and presented in Table 1. The comparison with the average H II region abundances (Garnett 1999) in the MCs shows slight variations, not easily imputable to physical conditions or systematic uncertainties.

\section{References}

Charmandaris, V., Heydari-Malayeri, M., Deharveng, L., et al. 2001, AAS 199, 124.05 Garnett, D. 1999, in: Y.-H. Chu, N.B. Suntzeff, J.E. Hesser, et al. (eds.), New Views of the Magellanic Clouds, Proc. IAU Symp. No. 190 (ASP: San Francisco), p. 266

Kurt, C., Dufour, R., Garnett, D., et al. 1999, ApJ 518, 246

Seaton, M.J. 1979, MNRAS (Letters) 187, 73P

Stasińska, G., Leitherer, C. 1996, ApJS 107, 661

Testor, G. 2001, A\&A 372, 667

Walborn, N., Fitzpatrick, E. 1990, PASP 102, 379 